Scientific note

\title{
A scientific note on the natural merger of two honeybee colonies (Apis mellifera capensis)
}

\author{
Peter NeumanN ${ }^{\mathrm{a}, \mathrm{b} *}$, Christian W.W. PirK ${ }^{\mathrm{a}, \mathrm{b}}$, Randall HePbuRN ${ }^{\mathrm{a}}$, Sarah E. RadLOFF ${ }^{\mathrm{c}}$ \\ ${ }^{a}$ Department of Zoology and Entomology, Rhodes University, 6140 Grahamstown, South Africa \\ ${ }^{b}$ Institut für Zoologie, Martin-Luther-Universität Halle-Wittenberg, Halle/Saale, Germany \\ c Department of Statistics, Rhodes University, 6140 Grahamstown, South Africa
}

(Received 3 October 2000; accepted 27 October 2000)

Apis mellifera capensis / honeybee / merger / spatial distribution / division of labor

Natural mergers of honeybee colonies are commonplace in tropical Africa (Hepburn and Radloff, 1998), but their consequences on organizational structure are unknown. Here we determine the spatial distribution and division of labor of workers (Apis mellifera capensis Esch.) following a merger of two colonies. Two unrelated colonies (each $\sim 3000$ bees) were placed in threeframe observation hives. When workers emerged from the sealed brood of each colony, they were individually labeled and reintroduced into their respective mother hives. They are referred to as cohorts A and B, each comprising 300 workers of the same age. The behaviors and positions of all labeled workers and queens were recorded twice daily for 24 days (Kolmes, 1989; Pirk et al., 2000). On day 14 colony B was dequeened, left its nest and merged with colony A on day 15 .

4357 individual behavioral acts (48 different tasks) and 2263 queen-worker distances (1422 before and 841 after merger) were recorded for 360 labeled bees. Severe fighting initially occurred at the nest entrance when the merger began but no aggression occurred once the workers of colony B had entered the nest of colony A. No significant differences in total activity (all tasks/idleness) and mean queen-worker distances of individuals bees were observed between the cohorts A and B before and after merger (Tab. Ia). However, total activity decreased and queen-worker distances increased after merger for the individual bees of both cohorts (Tab. Ia). There were significant differences among and

* Correspondence and reprints

E-mail: p.neumann@ @u.ac.za between tasks of cohorts A and B before and after merger (Tab. Ib). While some tasks increased and others decreased, the patterns of changes between cohorts differed (Tab. Ib). Daily counts of queen-worker distances were significantly different on four occasions before the merger but only once 24 hours after the merger (data not shown), demonstrating effective cohort integration. Also workers of both cohorts were similarly distributed throughout the nest after the merger.

On queen removal cohort B workers did not attempt to requeen but immediately merged with colony A. This may seem puzzling from an evolutionary perspective because the inclusive fitness of queenless workers is zero in the new unit. However, mergers are frequent in tropical honeybees (Hepburn and Radloff, 1998) and could be adaptive because workers may gain direct fitness. The lower levels of activity and the immediate increase in colony size after the merger probably reduce pro rata survival costs (Hepburn and Radloff, 1998). The origin of merging bees may matter, because task shifts differed in the two cohorts. This might be partially ascribed to age-related division of labor; however, this does not explain the substantial shifts observed both within and between the cohorts before and after the merger. Possibly, workers changed tasks as a result of different behavioral thresholds and task specialization (Moritz and Page, 1999). Thus, the possible acquisition of more efficient genetic specialists (Fuchs and Moritz, 1999) may also 
contribute to reducing pro rata costs in the new unit. The task shifts and worker distribution suggest that many bees responded to a different colony environment in the new unit, presumably necessary for social integration.

\section{ACKNOWLEDGEMENTS}

We are grateful to S. Fuchs and R.F.A. Moritz for valuable comments on the manuscript. Financial support was granted by the DFG (R.F.A. Moritz), the PPRI (HRH), a RU Fellowship (PN) and a DAAD Fellowship (CWWP).

Note scientifique sur la fusion naturelle de deux colonies d'abeilles (Apis mellifera capensis).

Eine wissenschaftliche Notiz zu der natürlichen Fusion zweier Honigbienenvölker (Apis mellifera capensis).

\section{REFERENCES}

Fuchs S., Moritz R.F.A. (1999) Evolution of extreme polyandry in honeybees (Apis mellifera), Behav. Ecol. Sociobiol. 45, 269-277.

Hepburn H.R., Radloff S.E. (1998) Honeybees of Africa, Springer, Berlin.

Kolmes S.A. (1985) An information-theory analysis of task specialisation among worker honey bees performing hive duties, Anim. Behav. 33, 181-187.

Moritz R.F.A., Page R.E. (1999) Behavioral threshold variability: costs and benefits in insect societies, in: Detrain C.J., Pasteels J., Deneubourg J. (Eds.), Information processing in Social Insects, Birkhäuser, Basel, pp. 203-215.

Pirk C.W.W., Polthier K., Neumann P., Preuss E. (2000) Estimating and visualizing the spatial distribution of individuals in social insect colonies, http://wwwsfb288.math.tu-berlin.de/ konrad/bees/.

Table I. Proportional comparisons for (a) individual workers and (b) whole cohorts A and B before and after the merger. Differences in total activity and mean queen-worker distances for individual bees were analyzed with Mann Whitney U-tests. Z-tests of proportions were used to test for significant differences in the task performances of the whole cohorts A and B: (i) for each cohort and the new colony and; (ii) to assess frequency changes of performances before and after merger between cohorts A and B. Only those behaviors are shown, where significant results have been obtained. Significant results are indicated with $*$ for $P<0.01$ and $* *$ for $P<0.001$ using Bonferroni adjustments $(\mathrm{N}=$ sample size, $P=$ significance level, $\mathrm{F}=$ frequency, new colony $=\mathrm{A}+\mathrm{B}$ combined $)$.

\begin{tabular}{|c|c|c|c|c|c|c|c|c|c|c|c|c|}
\hline \multirow[t]{2}{*}{ (a) Individual bees } & \multicolumn{5}{|c|}{ Before merger } & \multicolumn{5}{|c|}{ After merger } & \multicolumn{2}{|c|}{$\begin{array}{l}\text { Before } \\
\text { vs. After }\end{array}$} \\
\hline & Cohort A & $\mathrm{N}$ & Cohort B & $\mathrm{N}$ & 1 & Cohort A & $\mathrm{N}$ & Cohort B & $\mathrm{N}$ & $\mathrm{P}$ & $\begin{array}{l}\mathrm{A} \\
\mathrm{P}\end{array}$ & $\begin{array}{l}\mathrm{B} \\
\mathrm{P}\end{array}$ \\
\hline Total activity & $0.51 \pm 0.33$ & 170 & $0.51 \pm 0.28$ & 180 & & $0.29 \pm 0.30$ & 143 & $0.33 \pm 0.36$ & 118 & & $* *$ & $* *$ \\
\hline $\begin{array}{l}\text { Mean queen-worker } \\
\text { distance }\end{array}$ & $30.1 \pm 14.2$ & 167 & $31.1 \pm 11.9$ & 175 & & $43.3 \pm 13.9$ & 132 & $44.7 \pm 16.4$ & 106 & & $* *$ & $* *$ \\
\hline
\end{tabular}

\begin{tabular}{|c|c|c|c|c|c|c|c|c|c|c|c|c|}
\hline \multirow{3}{*}{$\begin{array}{l}\text { (b) Whole cohorts } \\
\text { Task }\end{array}$} & \multicolumn{3}{|c|}{ Cohort A } & \multicolumn{3}{|c|}{ Cohort B } & \multicolumn{3}{|c|}{ Changing patterns } & \multicolumn{3}{|c|}{ New colony } \\
\hline & Before & After & & Before & After & & $\mathrm{A}$ & B & & vs. & $\mathrm{A}$ & $\mathrm{B}$ \\
\hline & $\mathrm{F}$ & $\mathrm{F}$ & $\mathrm{P}$ & $\mathrm{F}$ & $\mathrm{F}$ & $\mathrm{P}$ & & & $\mathrm{P}$ & $\mathrm{F}$ & $\mathrm{P}$ & $\mathrm{P}$ \\
\hline Walk & 213 & 209 & $*$ & 246 & 123 & $*$ & -4 & -123 & $*$ & 332 & $*$ & $*$ \\
\hline Idleness & 478 & 903 & $*$ & 612 & 681 & $*$ & +425 & +69 & $*$ & 1584 & $*$ & $*$ \\
\hline Groom self & 49 & 15 & $*$ & 78 & 14 & $*$ & -34 & -64 & $*$ & 29 & $*$ & $*$ \\
\hline Inspecting empty/egg cell & 58 & 24 & $*$ & 104 & 22 & $*$ & -34 & -82 & $*$ & 46 & $*$ & $*$ \\
\hline Inspecting honey cell & 20 & 23 & & 38 & 9 & $*$ & +3 & -29 & $*$ & 32 & & $*$ \\
\hline Build comb & 1 & 8 & & 3 & 7 & & +7 & +4 & & 15 & $*$ & \\
\hline Groom other worker & 24 & 8 & $*$ & 27 & 4 & $*$ & -16 & -23 & & 12 & $*$ & $*$ \\
\hline Get groomed & 4 & 0 & & 10 & 0 & $*$ & -4 & -10 & & 0 & $*$ & $*$ \\
\hline Lateral shake & 1 & 0 & & 5 & 1 & & -1 & -4 & & 1 & & $*$ \\
\hline Dorsoventral abdominal vibration & 5 & 0 & $*$ & 2 & 0 & & -5 & -2 & & 0 & $*$ & \\
\hline Begging for food & 2 & 0 & & 2 & 22 & $*$ & -2 & +20 & $*$ & 22 & $*$ & $*$ \\
\hline Attend queen & 6 & 0 & $*$ & 1 & 0 & & -6 & -1 & & 0 & $*$ & \\
\hline Antennate with worker & 52 & 26 & $*$ & 61 & 12 & $*$ & -26 & -49 & $*$ & 38 & $*$ & $*$ \\
\hline Run (move faster $\sim 3 \mathrm{~cm} / \mathrm{s}$ ) & 4 & 0 & & 12 & 1 & $*$ & -4 & -11 & & 1 & $*$ & $*$ \\
\hline Forage & 1 & 1 & & 0 & 4 & $*$ & 0 & +4 & & 5 & & \\
\hline Wax chain & 0 & 15 & $*$ & 0 & 10 & $*$ & +15 & +10 & & 25 & $*$ & $*$ \\
\hline
\end{tabular}

